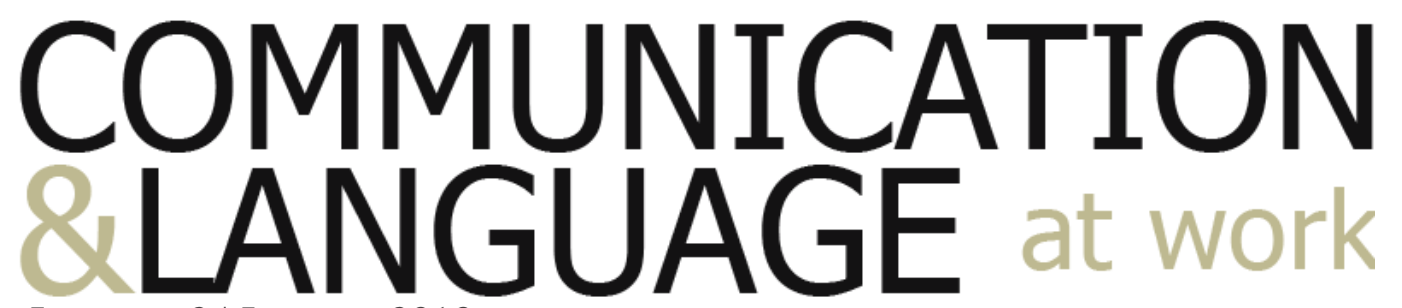

Issue no. 2 | January, 2013

Technical Communication

\title{
Teaching Workplace Skills to Technical Communicators
}

\section{Darina M. Slattery \& Yvonne Cleary}

(pp. 20-25)

http://ojs.statsbiblioteket.dk/index.php/claw/article/view/7897

Subscribe:

http://ojs.statsbiblioteket.dk/index.php/claw/notification/subscribeMailList

Archives:

http://ojs.statsbiblioteket.dk/index.php/claw/issue/archive

\section{Publishing:}

http://ojs.statsbiblioteket.dk/index.php/claw/about/submissions\#onlineSubmissions

\section{Contact:}

http://ojs.statsbiblioteket.dk/index.php/claw/about/contact

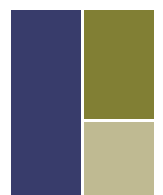

| Bridging Theory and Practice |

http://ojs.statsbiblioteket.dk/index.php/claw 


\title{
Teaching Workplace Skills to Technical Communicators
}

\author{
Darina M. Slattery \\ Lecturer and Programme Director \\ School of Languages, Literature, Culture and Communication \\ University of Limerick \\ Yvonne Cleary \\ Lecturer and Programme Director \\ School of Languages, Literature, Culture and Communication \\ University of Limerick
}

\begin{abstract}
In this article, we introduce two programmes in Technical Communication (one distance, and one on-campus) offered by the University of Limerick. Both programmes have been running for several years, but are regularly reviewed to ensure that they remain relevant. We describe how these programmes correspond to industry needs, and how they develop core competencies of technical communicators. We outline two key types of assignment (writing and development), and explain their relevance to the workplace.
\end{abstract}

\section{Introduction}

Since 1996, the University of Limerick (UL), in Limerick, Ireland, has offered programmes in Technical Communication. In a 1996 article for the Journal of Technical Writing and Communication, John Kirkman described the development of the MA in Technical Communication at UL, emphasising its links with industry. The Technical Communication offerings at Limerick have changed in the intervening 16 years since Kirkman was involved in establishing the MA programme. For example, undergraduate students in New Media degree programmes study Technical Communication courses, a distance learning Certificate in Technical Writing has run since 2001, and most recently an MA in Technical Communication and E-Learning has replaced the original MA in Technical Communication. The links with industry, however, remain strong, and have proved invaluable in enabling us to update programme and course content.

In this article, we present an overview of two Technical Communication programmes offered by UL. We outline some courses that are included in both programmes, and the types of assignments that students are required to undertake, prior to entering the workforce. We discuss the range of skills students are required to demonstrate in assignments, including writing, information design, and development skills. 


\section{Our programmes}

The Technical Communication Section at UL currently offers two postgraduate programmes: a Graduate Certificate in Technical Writing (distance learning) and an MA in Technical Communication and E-Learning (on-campus). Faculty members also teach courses on several undergraduate programmes. Both postgraduate programmes offer a number of shared modules, which have been designed to prepare students for the workplace. Because our students come from a variety of disciplines including the Arts, Sciences, and Engineering, these are conversion programmes, which have been designed to enable students to re-skill. Whilst some of our students have experience working in relevant fields (Technical Writing, Instructional Design, and Content Development), the majority have no prior experience, so our programmes assume no prior knowledge.

On successful completion of either programme, our graduates are able to:

- Design and deliver instructional materials.

- Use multimedia applications to create content.

- Deploy and use Web 2.0 technologies to collaborate with peers.

- Manage complex writing and design projects.

- Communicate effectively in online and face-to-face environments.

- Write clear, correct and precise content.

Many graduates find employment as Content Developers in large software development companies, which typically have their own documentation departments. Other graduates find employment as Technical Writers or Trainers in companies. As reflected in other countries (see, for example, Spilka 2002 and Giammona 2004) job titles for graduates are diverse, however, and some, such as 'Digital Content Specialist' and 'Content Curator', reflect the centrality of new technologies.

Since its inception, several hundred graduates of UL have completed undergraduate modules or full programmes at Graduate Certificate, Diploma and MA levels in Technical Communication. Many of these graduates now have ten to fifteen years of industry experience. We are fortunate to have retained links with many graduates, and to have cultivated links with employers. Therefore, we are able to run workplace seminars where Technical Writers, Content Developers, and Documentation Managers share experiences and tips with current students. This interaction with industry also enables us to ensure that programme curricula respond to industry needs. 


\section{Courses and assignments}

Students undertake a range of courses on both programmes. Whilst the MA programme offers more courses, there is some overlap. Students on both programmes take courses on professional and technical writing, the theory of technical communication, workplace issues, and instructional design. These courses include content on topics central to the work of a technical communicator. A report from TCEurope's TecDoc-Net project (2005) lists the following core competencies for technical communicators in Europe: communication theory; understanding and using tools; [knowledge of] the regulatory framework; project and process management; information gathering; documentation planning and information development; usability; structuring information; standardisation techniques; professional writing; editing; visual communication; layout and typography.

Content on four core courses on both programmes helps students to develop these core competencies. Students study communication and writing theories, learn how to use tools, learn to manage complex design projects, conduct research and planning activities, develop information projects, apply information design theories, and learn about quality and standards. As both programmes comprise $100 \%$ continuous coursework, students undertake a number of assignments each semester, including writing assignments and design and development assignments. The assignments described in the next section demonstrate how students develop some competencies identified by the TecDoc-Net project.

Both programmes use the UL Virtual Learning Environment for delivery of various programme elements. On- and off-campus students follow and contribute to online discussions, submit assignments, receive feedback on assignments, collaborate with peers, access e-resources, and participate in online chats.

\section{Writing assignments}

The writing assignments students complete as part of both programmes include short summaries, rewrites of text passages, essays, and extensive research reports. Students receive marks not only for the quality and clarity of their writing, but also for their information design and overall formatting skills. For example, for research reports students are expected to research and write about a topic of relevance to the field. They are also expected to generate a Table of Contents automatically and to format cited references according to the Harvard (author-date) referencing style. We also emphasise the need to write for international audiences, and students learn to apply guidelines such as those developed by Kohl (2008). These writing skills prove invaluable when students enter the workplace, where they will regularly be required to write documentation for many different genres and audiences. 


\section{Design and development assignments}

In addition to studying theory relating to technical writing and information design, students also learn how to use a range of industry-standard software applications, including Adobe Captivate, Dreamweaver, Flash, and Photoshop. In practical assignments, students are required to demonstrate not only their software skills but also their ability to apply their knowledge of design and communication theories, to design and development assignments. For example, students are required to find examples of poor graphics and to critique them. They are also required to improve the graphics by redesigning them. Other practical assignments include the redesign of existing brochures, the development of instruction manuals, the design of web sites and interactive animations, and the development of e-learning courses. For some of these assignments, students are required to collaborate with peers both online and face-toface, to produce a fully workable product. In other assignments, students must work on a real-world project, communicating with a client about requirements, to produce an end product that is appropriate for the needs of a specific audience. These types of assignments help students to become more critically aware of content they see on a daily basis, to improve their collaboration skills, and to develop their design and development skills. Such skills are in demand in the workplace, and our graduates have a very successful employment record on completion of both programmes.

\section{Conclusions}

In a young and dynamic discipline such as Technical Communication, academic programmes need to have close links with industry in order to ensure that graduates will be appropriately prepared for the workplace. Lecturers need to remain abreast of disciplinary and industry changes to ensure that the curriculum is fresh and relevant. Our paper describes some programme features and assignments that prepare graduates to work as Technical Writers and Content Developers, and in related fields. 


\section{C ommunication \& Language at Work}

\section{References}

Giammona, B.A. (2004) "The future of technical communication: how innovation, technology, information management, and other forces are shaping the future of the profession", Technical Communication, 51(3), 349-366.

Kirkman, J. (1996) "From chore to profession: how technical communication in the United Kingdom has changed over the past twenty-five years", Journal of Technical Writing and Communication, 26(2), 147-154.

Kohl, J. (2008) The Global English Style Guide, Cary, NC, USA: SAS Press.

Spilka, R. (2002) "Becoming a profession", in Mirel, B. and Spilka, R., eds., Reshaping Technical Communication: New Directions and Challenges for the $21^{\text {st }}$ Century, Mahwah, NJ: Lawrence Erlbaum Associates, 97-110.

TCEurope (2005) "Professional education and training of technical communicators in Europe-guidelines", TecDoc-Net Project, [online], available: http://www.tceurope.org/images/stories/downloads/projects/tecdoc.pdf [accessed 03 December, 2012]. 


\section{Communication \& Language at Work}

\section{Authors}

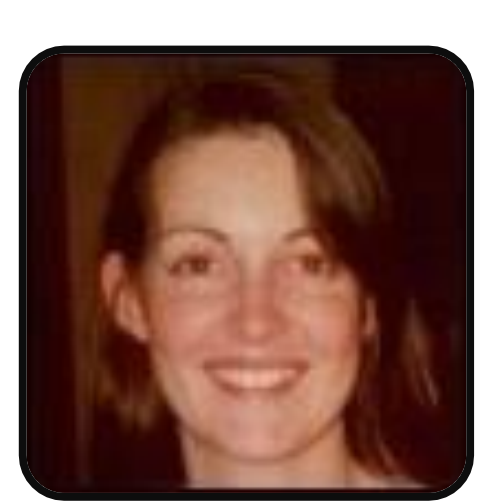

Darina M. Slattery

Lecturer and Programme Director

Section Leader: Technical Communication, School of

Languages, Literature, Culture and Communication,

University of Limerick.

Darina M. Slattery holds a PhD in Computer Science, an MSc in Software Localisation, and a Bachelor of Business Studies with French Degree. She has been teaching technical communication, instructional design, and e-learning design and development at the University of Limerick since 2003 and has published her research in refereed journals and international conference proceedings. Her teaching and research interests include e-learning design and development, technical communication theory, virtual teams and information design. She is Programme Director for the Graduate Certificate in Technical Writing programme, which is offered by distance learning.

\section{Contact:}

\section{Darina.Slattery@ul.ie}

School of Languages, Literature, Culture and Communication, University of Limerick, Limerick, Ireland.

Web: http://www.ul.ie/techcomm

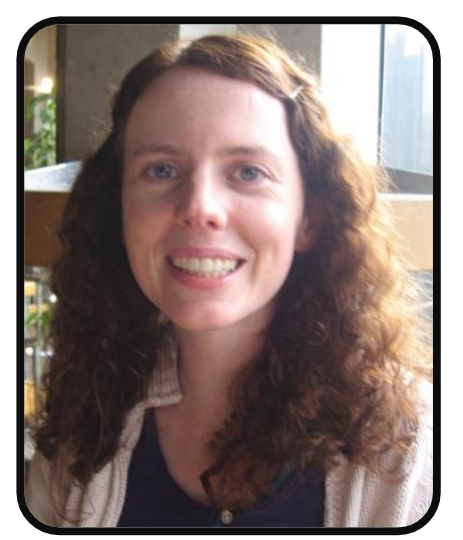

Yvonne Cleary

Lecturer and Programme Director

Associate Head: School of Languages, Literature, Culture and Communication, University of Limerick.

Yvonne Cleary is a lecturer in Technical Communication at the University of Limerick, where she is Programme Director for the MA in Technical Communication and E-Learning. She teaches courses on the theory and practice of technical communication. Her research interests include international communication, virtual teams, and the Irish technical communication field. She holds an MA and $\mathrm{PhD}$ in Technical Communication. She has presented her research at international conferences and has published in leading journals including: Journal of Technical Writing and Communication, Technical Communication and IEEE Transactions on Professional Communication.

\section{Contact:}

Yvonne.Cleary@ul.ie

School of Languages, Literature, Culture and Communication,

University of Limerick, Limerick, Ireland.

Web: http://www.ul.ie/techcomm 